Bull. Mater. Sci., Vol. 20, No. 6, September 1997, pp. 817-822. (C) Printed in India.

\title{
Application of MO calculation to plasma-enhanced CVD using organosilicon compounds
}

\author{
OSAMU TAKAI*, ATSUSHI HOZUMI, YASUSHI INOUE and \\ TAKASHI KOMORI
}

Department of Materials Processing Engineering. Nagoya University, Chikusa-ku, Nagoya 464-01, Japan

\begin{abstract}
Ultra water-repellent films for which contact angles of water drops exceed $150^{\circ}$ were prepared by microwave plasma-enhanced CVD using two kinds of organosilicon compound and fluoro-alkyl silane (FAS) at low substrate temperature. Hexamethyldisilane (HMDS) and hexamethyldisiloxane (HMDSO) were used as starting materials. Molecular orbital (MO) calculation suggested that HMDS was more easily decomposable than HMDSO. The films prepared with HMDS and FAS had ultra water repellency. On the other hand, water repellency of the films prepared with HMDSO and FAS was similar to that of polytetrafluoroethylene.
\end{abstract}

Keywords. MO calculation; plasma enhanced CVD; water repellency.

\section{Introduction}

Water repellency is required in various fields. Especially ultra water repellency, where the contact angle of a water drop exceeds $150^{\circ}$, has become of major interest lately. Many studies on the ultra water-repellent treatment by plasma have been reported to date (Kogama et al 1987; Goto et al 1991; Matsui et al 1992; Takada et al 1993; Yokoi et al 1993). However, there are no reports of preparation of ultra water-repellent films by plasma-enhanced CVD (PECVD).

In a previous report, we prepared ultra water-repellent films by microwave PECVD using tetramethylsilane (TMS) and fluoro-alkyl silane (FAS) (Hozumi et al 1997). The obtained contact angle of a water drop was about $160^{\circ}$.

The selection of a starting material is important since the starting material greatly affects the growth, composition and properties of deposited films. In this study, molecular orbital (MO) calculation was carried out to predict suitable organosilicon compounds, except TMS, for preparing ultra water-repellent films. We also studied the film properties by contact angle measurement, X-ray photoelectron spectroscopy (XPS), Fourier transform infrared spectroscopy (FTIR) and atomic force microscopy (AFM).

\section{Calculation and experiment}

We carried out the MO calculation for organosilicon compounds used in the experiment. MOPAC (version 6.01) was used for the MO calculation. We optimized

*Author for correspondence 
the geometries of the organosilicon compounds by using Pople's bond lengths and angles as starting geometries. Organosilicon compounds used were hexamethyldisilane (HMDS) and hexamethyldisiloxane (HMDSO). The molecular structures of these reactants are very similar. FAS used for a water-repellent source was (heptadecafluoro-1,1,2,2-tetrahydro-decyl)-1-trimethoxysilane. We will call this FAS-17 hereafter. Microwave PECVD apparatus was used to prepare ultra waterrepellent films on $\mathrm{Si}$ and glass substrates. The reactor was evacuated below $1 \mathrm{~Pa}$ by a rotary pump and then the vapours of these reactants were introduced through gas inlets just above substrates. Ar was used as a carrier gas of FAS-17 because it had higher boiling point $\left(85-87^{\circ} \mathrm{C} / 133 \mathrm{~Pa}\right)$ than both HMDS and HMDSO. The flow rate of $\mathrm{Ar}$ was kept constant at $20 \mathrm{sccm}$ by a mass flow controller and the temperature of the vaporizer of FAS-17/Ar was kept at $70^{\circ} \mathrm{C}$. The gas line for FAS-17/Ar was heated to prevent condensation of vapour. The temperature of vaporizer of HMDS or HMDSO was around room temperature. The partial pressure ratio of an organosilicon compound to FAS-17/Ar was fixed at 1 . The total pressure was changed from 25 to $50 \mathrm{~Pa}$. Microwave power was fixed at $300 \mathrm{~W}$. Water repellency was estimated by measuring contact angles of water drops with a contact angle meter (Model: CA-X150, Kyowa Interface Science Co. Ltd). Chemical bonding states of deposited films were studies by using a FTIR system (Model: FT-IR 5300, JEOL) and an XPS system (Model: ESCA 1000, Shimadzu Co. Ltd). We investigated surface morphology of the films by AFM (Model: SPA 300, SII Co. Ltd).

\section{Results and discussion}

\subsection{Electronic states and reactivity}

Table 1 shows the frontier orbital energies and the two centre bond energies of HMDS and HMDSO calculated by MOPAC. Energy difference between HOMO and LUMO of HMDS is smaller than that of HMDSO. Furthermore, the bond energy of $\mathrm{Si}-\mathrm{Si}$ bond is much weaker than that of $\mathrm{Si}-\mathrm{O}$ bond. Therefore, it is expected that HMDS is easily excited and decomposed to reactive species in plasma.

\subsection{Preparation of ultra water-repellent films}

The deposition rates of the films were quite different between HMDS and HMDSO. The highest deposition rate was about $230 \mathrm{~nm} / \mathrm{min}$ when HMDS and FAS-17/Ar were used at $50 \mathrm{~Pa}$. This rate was twice as high as the rate obtained when HMDSO and FAS-17/Ar were used at the same pressure.

Table 1. Fronticr orbital encrgies and two centre bond energies calculated for organosilicon compounds by MOPAC.

\begin{tabular}{lcccccccc}
\hline & \multicolumn{3}{c}{ Energy level (eV) } & & \multicolumn{4}{c}{ Bond energy (eV) } \\
\cline { 2 - 4 } \cline { 7 - 9 } & LUMO & HOMO & $\Delta E$ & & Si-Si & Si-O & Si-C & C-H \\
\hline HMDS & -0.84 & -8.45 & 7.61 & -6.53 & - & -10.97 & -12.66 \\
HMDSO & 1.22 & -9.29 & 10.51 & - & -14.89 & -11.00 & -12.66 \\
\hline
\end{tabular}


Figure 1 shows the relationships between the total pressures of reactants and the contact angles. The partial pressure ratio of HMDS or HMDSO to FAS-17/Ar was fixed at 1. The contact angles increase with total pressure for both sources. However the remarkable difference in the maximum contact angles is observed. For the films prepared with HMDS and FAS-17/Ar, the contact angle increases remarkably with total pressure and reaches the maximum value (about $160^{\circ}$ ) at the total pressure $50 \mathrm{~Pa}$. On the other hand, for the films prepared with HMDSO and FAS-17/Ar, the maximum contact angle is about $110^{\circ}$ which is comparable to the contact angle for polytetrafluoroethylene (PTFE, 108 ) (Yano et al 1989). The colour of the films prepared with HMDS and FAS-17/Ar changes from light yellow to dark white with increasing total pressure. The transparency is kept over $90 \%$ up to the total pressure of $30 \mathrm{~Pa}$, but decreases remarkably at 40 and $50 \mathrm{~Pa}$. On the other hand, the transparency of the films prepared with HMDSO and FAS-17/Ar is kept over $90 \%$ at all the total pressures.

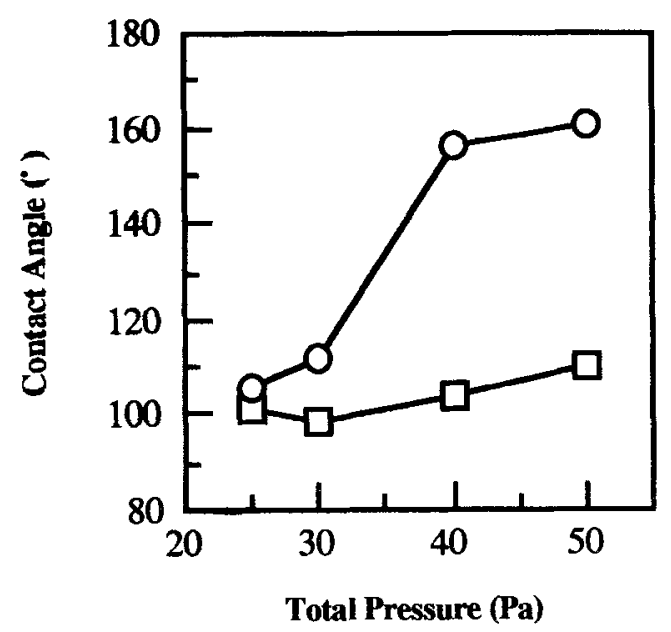

Figure 1. Relationshup between tine letil presume of reactants and the contact angles;

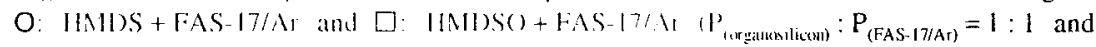
$T=71)(1)$

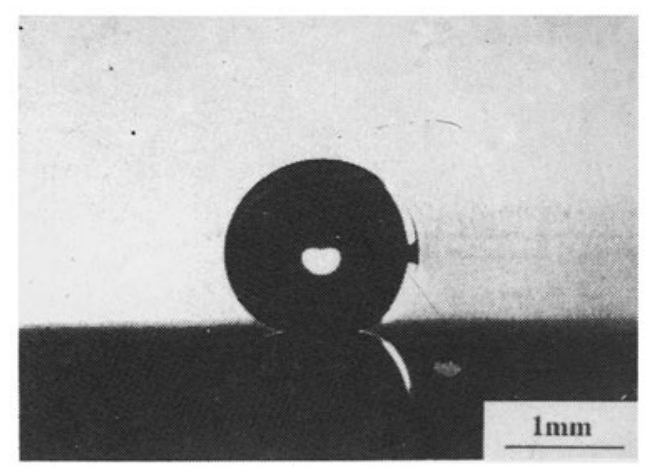

Figure 2. Photograph of a water drop on the film deposited onto $\mathrm{Si}$ substrate to demonstrate

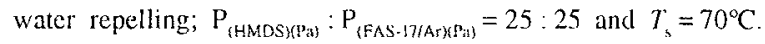


Figure 2 shows the photograph of a water drop on the film prepared with HMDS and FAS-17/Ar deposited onto glass at the total pressure of $50 \mathrm{~Pa}$ to demonstrate water repelling. The water drop on the film is completely globular and the water repellency is improved remarkably because the contact angle of the initial glass plate is about $27^{\circ}$.

Generally, it is necessary to cover surfaces with low surface energy materials such as PTFE to add water repellency on the substrate surfaces. Wenzel (1936) reported that the contact angle increased in appearance in the case of existence of 凸 at the surface. It is necessary, therefore, to satisfy these two conditions and at the same time obtain ultra water repellency. Next FTIR and XPS measurements were performed to investigate chemical bonding states. AFM observation was also carried out to investigate surface morphology of the films.

\subsection{Structural analysis}

Figure 3 shows the IR spectra of the films deposited onto $\mathrm{Si}$ wafers at the total pressure of $50 \mathrm{~Pa}$. In both spectra, three absorption bands due to the asymmetric $\mathrm{Si}-\mathrm{O}-\mathrm{Si}$ stretching, deformation and rocking vibrations are detected at 1090, 810 and $420 \mathrm{~cm}^{-1}$ (Socrates 1994). In the spectrum (a), bands due to the $\mathrm{C}-\mathrm{F}$ stretching vibration in the $-\mathrm{CF}_{2}$ - and $\mathrm{CF}_{3}$-groups are detected at $1120-1350 \mathrm{~cm}^{-1}$ and a band due to the $\mathrm{Si}-\mathrm{C}$ deformation vibration in the $\mathrm{Si}-\mathrm{CH}_{3}$ groups also appears at $880 \mathrm{~cm}^{-1}$

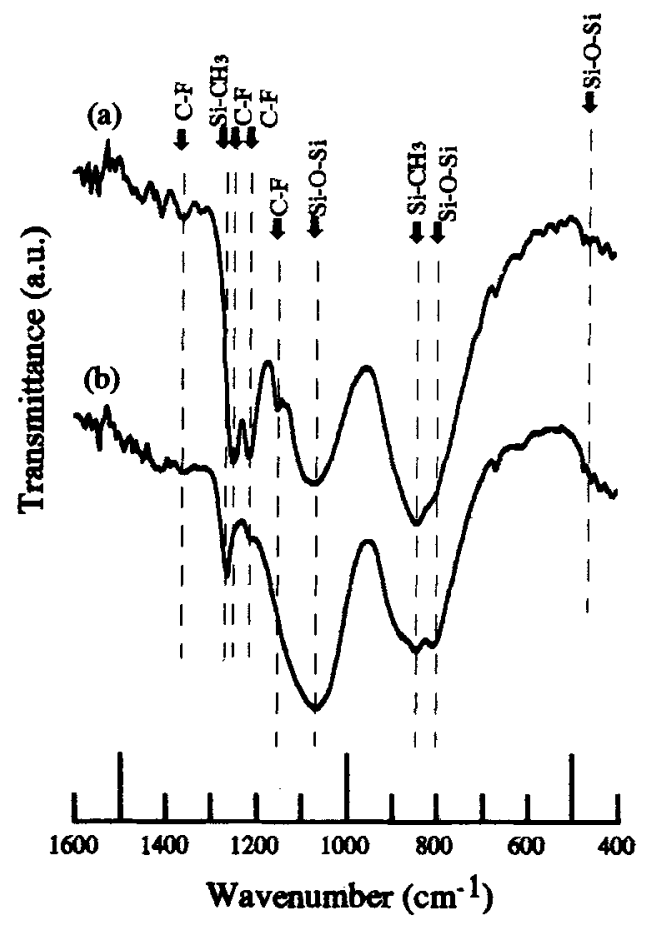

Figure 3. IR spectra of the deposited films: (a) HMDS + FAS-17/Ar and (b) HMDSO + FAS-17/Ar. 
(Socrates 1994). On the other hand, in the spectrum (b), these bands become unclear.

The chemical composition at the surfaces of the films prepared at $50 \mathrm{~Pa}$ was measured by XPS without Ar etching. The Si, O, C and F concentrations of the film prepared with HMDS and FAS-17/Ar are 27.5, 12.4, 47.0 and 13.1 at $\%$. On the other hand, for the film prepared with HMDSO and FAS-17/Ar, they are 33.7, $15.8,41.5$ and 9.0 at\%. Both the increase in $\mathrm{O} / \mathrm{F}$ value which shows the increase in hydrophilic factor and the decrease in $\mathrm{C} / \mathrm{Si}$ value which shows the decrease in organic nature are observed when HMDSO and FAS-17/Ar are used.

Figures $4 \mathrm{a}$ and $\mathrm{b}$ show the AFM images of the surfaces of the films prepared with HMDS and FAS-17/Ar, and HMDSO and FAS-17/Ar. The surface of the film prepared with HMDSO and FAS-17/Ar is much smoother than that of the film prepared with HMDS and FAS-17/Ar. $R_{\mathrm{ms}}$ values of the surfaces of the films prepared with HMDS and FAS-17/Ar, and HMDSO and FAS-17/Ar are 45 and $17 \mathrm{~nm}$. From FTIR and XPS measurements it has been shown that water repellency is affected not only by surface chemical bonding states but also surface morphology.

Generally the formation of polymerized particles is observed when the polymerization rate is very high in the PECVD process (Osada 1986). Despite the similar structures between HMDS and HMDSO, the remarkable difference in the deposition rate and deposits is observed. This is due to the existence of oxygen atoms in HMDSO. Liepins et al (1975) reported on the process about the uniform coating
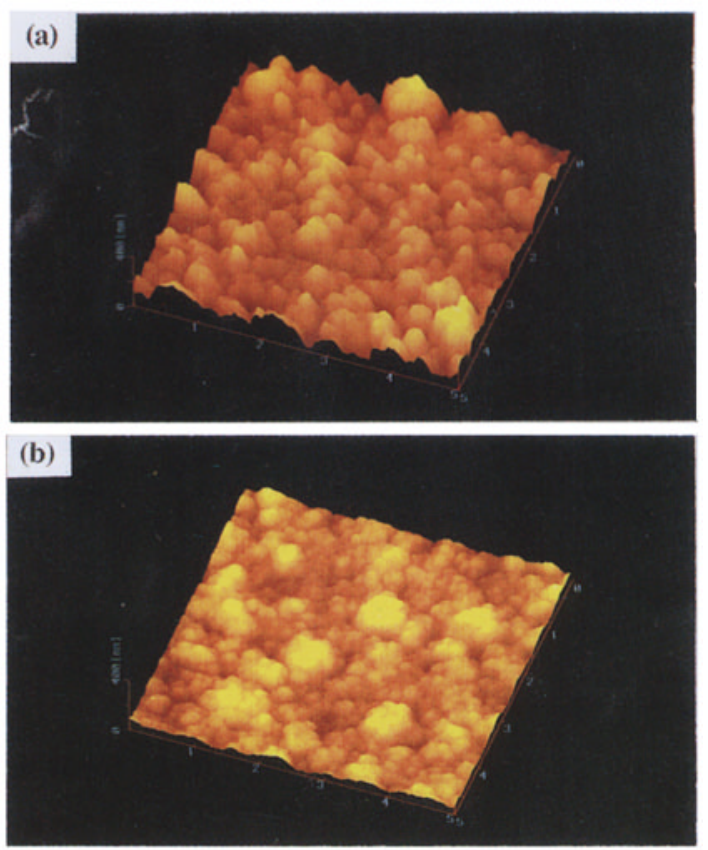

Figure 4. AFM images of the deposited film surfaces prepared with (a) HMDS and FAS-17/Ar and (b) HMDSO and FAS-17/Ar at $T_{v}=70^{\circ} \mathrm{C}$; scales of $\mathrm{x}, \mathrm{y}$ and $\mathrm{z}$ axes are $5 \mu \mathrm{m}, 5 \mu \mathrm{m}$ and $400 \mathrm{~nm}$. 
of the films. The oxygen was pulsatively introduced into the plasma. This process promoted the formation of the chemically active sites and enabled an overall surface smoothing. Oxygen plays an important role in the shape of the deposits. Therefore, oxygen atoms in the organosilicon compounds also affect the deposits in this study.

\section{Conclusions}

Ultra water-repellent films were prepared by microwave PECVD using an organosilicon compound and FAS-17/Ar. Ultra water-repellent films were obtained when HMDS and FAS-17/Ar were used at 50 Pa. Remarkable difference between HMDS and HMDSO was observed. MO calculation supports the experimental result. Water repellency is affected by not only surface chemical bonding states but also surface morphology.

\section{References}

Goto T, Chen J and Wakida T 1991 Chemistry Express 6711

Hozumi A, Kondo T, Kajita I and Takai O 1997 Thin Solid Films 303222

Kogama M, Kasai H, Takahashi K, Moriwaki T and Okazaki S 1987 J. Phys. D: Appl. Phys. 20147 Liepins R, Campbell M and Fries R J 1975 Prep. Am. Chem. Soc. Div. Org. Coat. Plast. Chem. 40 175

Matsui H, Setoyama K and Kurosu H 1992 J. Jpn Wood Res. Soc. 3873

Osada Y 1986 Plasma polymerization (Tokyo: Tokyo Kagakudojin) p. 82

Socrates G 1994 Infrared characteristic group frequencies-tables and charts (Chichester: John Wiley \& Sons) 2nd ed., p. 157

Takada Y, Soga M, Ogawa K and Ozaki S 1993 Polymer Preprints Jpn 421719

Wenzel R W 1936 End. Eng. Chem. 28988

Yano H, Mori K, Koshiishi K and Masuhara K 1989 J. Surf. Fin. Soc. Jpn 40110

Yokoi S, Kanzaki M, Kikuchi K, Ideue H, Ichikawa M and Endo E $1993 \mathrm{~J}$. Soc. Rubber Ind. Jpn 66102 